\title{
Light emitting tube for giant color display
}

\author{
Hiroo KOBAYASHI* and Kenzo AWAZU**
}

\begin{abstract}
A giant outdoor, full color display system has been developed, the display screen consisting of a matrix array of newly developed light emitting tubes. Each tube is a flood beam CRT, which works as a single picture element (one color), having a single red, green or blue phosphor. The tube is enveloped by a colored glass bulb, to maintain high contrast in bright daylight. It has many superior characteristics and features high color fidelity, low power consumption and long life. It is most suitable for outdoor color display.
\end{abstract}

\section{Introduction}

In the conventional construction of giant color display systems, as in electric light display boards used in baseball fields or apparatus to display advertising, etc. on roof tops or building walls, pictures have been formed by selectively switching on and off a multitude of electric light bulbs arranged in a pre-determined pattern.

Such display systems have had many difficult problems to be solved, for example, it may first be mentioned that color retention is poor. This originally resulted from the fact that electric light bulbs produce colors as a result of heating the filament until red hot, giving a red or light orange color. Therefore, in order to produce the three colors separately as red, green and blue, to reproduce color pictures, light beams from the respective filaments have to be picked up through colored glass, to separate each color. However, as the light source, i.e. the electric light bulb has, fundamentally, a small quantity of the green component and, more particularly, of the blue, it has been extremely inefficient in picking up those colors. Furthermore, electric light bulbs of more than 15 watts have generally been employed, and each display system has included several tens of thousands of such electric light bulbs, thus causing major problems of power consumption, heat generated by the individual bulbs, reliability, maintenance, etc.

To overcome these problems, we have developed light emitting tubes, arranging them in matrix array to produce a display system having low power consumption and presenting natural color pictures in daylight.

* Mitsubishi Electric Corporation, Kyoto Works, Kyoto, Japan

** Mitsubishi Electric Corporation, Central Research Laboratory, Amagasaki, Japan

\section{Characteristics of the Lighting Tube}

\section{1 Outline and Dimensions}

The lighting tube is a flood beam CRT having a single aluminised phosphor screen of red, green or blue. The tube is enveloped by a colored glass bulb, so as to maintain high contrast in bright daylight and ensure high color fidelity.

Fig. 1 shows the construction of this tube. Anode voltage is supplied from the base, thereby permitting easy arrangement of a great number of tubes.

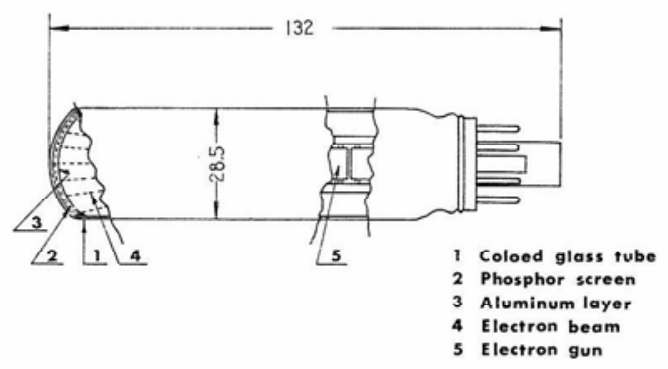

Fig. 1 Construction of the light emitting tubes.

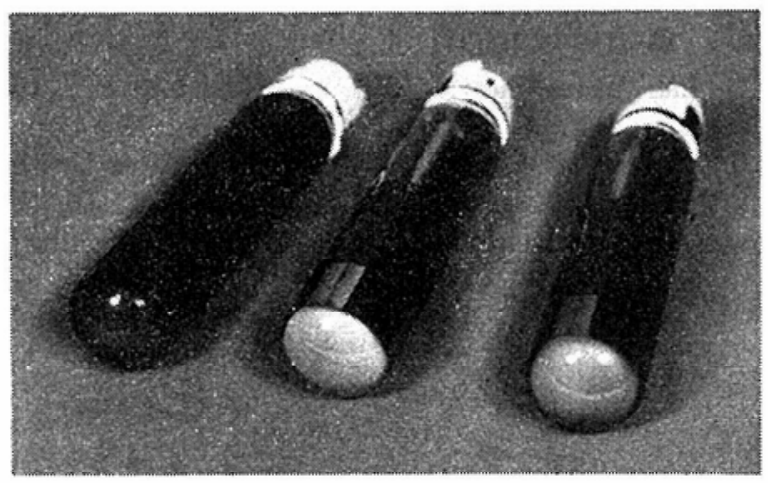

Fig. 2 Light emitting tubes. 
Mechanical dimensions are $28.6 \mathrm{~mm}$ diameter and $132 \mathrm{~mm}$ overall length. Power consumption per tube is approximately 2.0 watts, including power supply (See Fig. 2).

\section{2 Optical characteristics}

Fig. 3 shows the transmission curve of each colored glass, and the phosphor spectral emission characteristics are as shown in Fig. 4; $\mathrm{ZnS}: \mathrm{Ag}$ in blue, $\mathrm{Gd}_{2} \mathrm{O}_{2} \mathrm{~S}: \mathrm{Tb}$ in green and $\mathrm{Y}_{2} \mathrm{O}_{2} \mathrm{~S}: \mathrm{Eu}$ in red. Having combined the colored glass and the phosphor, (see Figs. $3 \& 4$ ) the lighting tube, serving as a light source, provides high contrast even in the daytime because unrequired ambient light is absorbed by the colored glass. ${ }^{1)}$

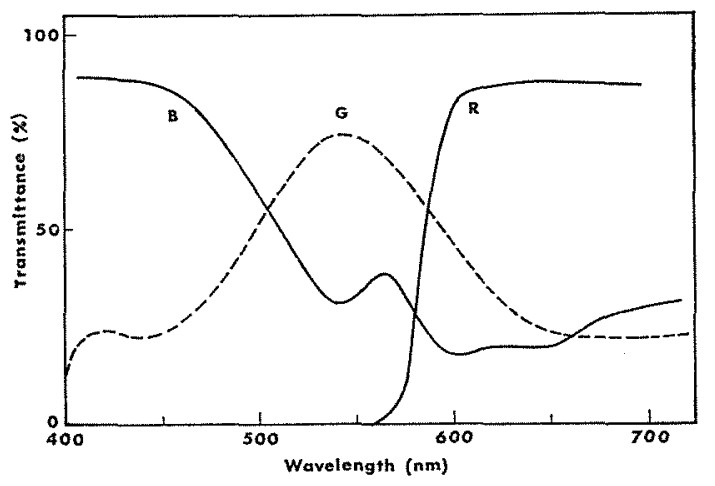

Fig. 3 Transmission of each colored glass $(R, G \& B)$

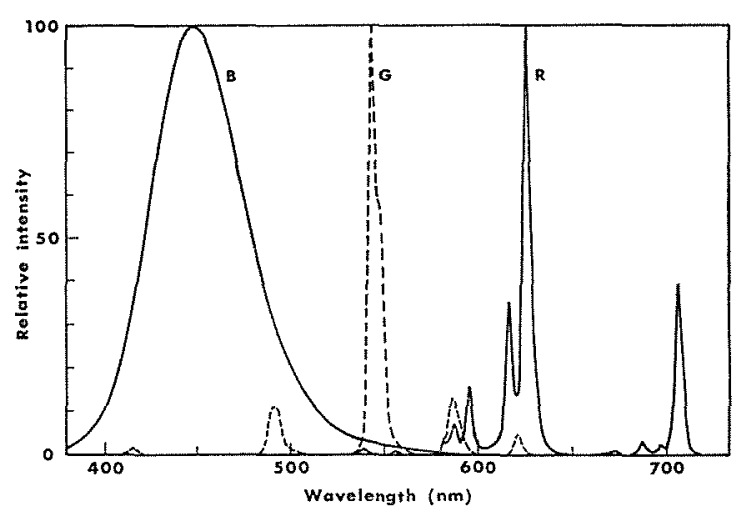

Fig 4 Emission spectrum of the 3 phos. phors

Fig. 5 shows chromaticity on the screen for each lighting tube; each angle of the triangle showing chromaticity points of red, green and blue, and each " $x$ " marked point indicating the chromaticity of the phosphor itself. It is clear from the figure that chromaticity of each color is greatly improved over the area of color gamuts, using colored glass.

The color gamut of these tubes can be extended by about $35 \%$ more than that of the phosphors under nil ambient light.

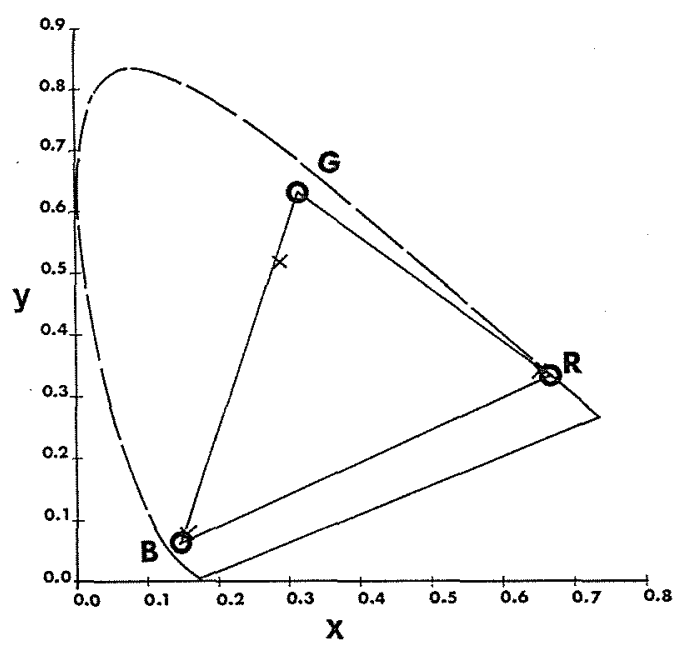

Fig, 5 Chromaticity of blue, green and red light emitting tubes.

Since these display systems employ a brightness control technique based on duty control'), unlike the conventional beam current control, the phosphor's gamma characteristic and change in light emitting area become negligible. 2Typical chromaticity and brightness characteristics are shown in Table 1 .

Table 1 Typical chromaticity and brightness characteristics of light emitting tubes.

\begin{tabular}{|c|c|c|c|c|}
\hline \multirow{2}{*}{\multicolumn{2}{|c|}{ Phosphor }} & \multicolumn{2}{|c|}{$\begin{array}{c}\text { Chromaticities } \\
\text { Value CIE }\end{array}$} & \multirow{2}{*}{$\begin{array}{c}\text { Brightness } \\
\text { nt }\end{array}$} \\
\hline & & $\mathrm{x}$ & $\mathrm{y}$ & \\
\hline B & $\mathrm{ZnSAg}$ & 0.1472 & 0.0642 & 1700 \\
\hline G & $\mathrm{Gd}_{2} \mathrm{O}_{2} \mathrm{~S} \mathrm{~Tb}$ & 0.3134 & 0.6310 & 8000 \\
\hline $\mathrm{R}$ & $\mathrm{Y}_{2} \mathrm{O}_{2} \mathrm{~S} \mathrm{Eu}$ & 0.6661 & 0.3329 & 4200 \\
\hline
\end{tabular}

Problems have been experienced with the colored glass. The red glass, in particular, has caused many difficulties in mass-production, i.e. low productivity, color variation and environmental pollution due to the colorant.

We have also been studying improvement of the optical characteristics of colored glass. As a result, we have found new colorants for this glass which produce selective spectral transmission characteristics ${ }^{3)}$. Color stability of the tube and productivity of the lighting tube glass bulb have been greatly improved.

\section{Conclusion}

The developed tube has many superior characteristics and is most suitable for outdoor full color display.

The features are:

(1) High brightness and high color fidelity ensure sharp pictures even in bright daylight.

(2) Fast response, ensuring operation at 60 fields per second.

(3) Low power consumption, e.g. $80 \mathrm{kVA}$ for a 
$10.8 \mathrm{~m} \times 7.2 \mathrm{~m}$ screen size (38,400 tubes).

(4) Long operating life (more than 8,000 hours at half brightness point).

The first giant color display system was unveiled at the Dodger Stadium in Los Angeles, USA, on July 8, 1980, to show instant replays and action close-ups in the 1980 All-Star baseball game. Since then, world-wide interest in this display system has been considerable. These systems give an exsample in Fig. 6 and Fig. 7.

In future, we think this color display system will expand to a variety of applications, for ex-

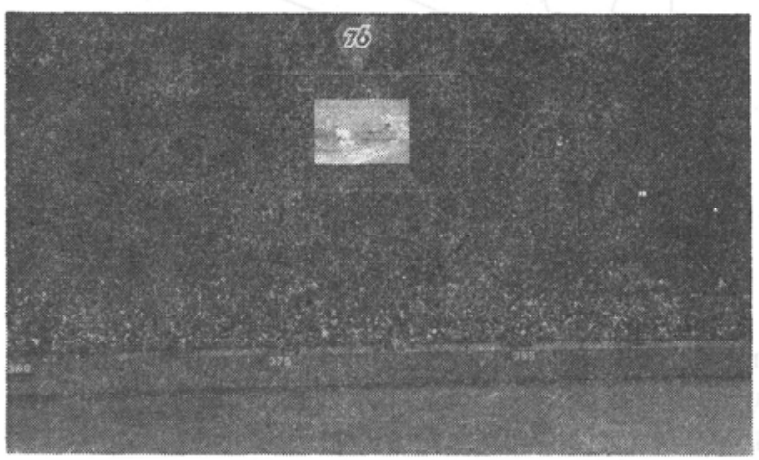

Fig. 6 Giant Display System Installed at the Dodger Stadium, Los Angeles, USA.

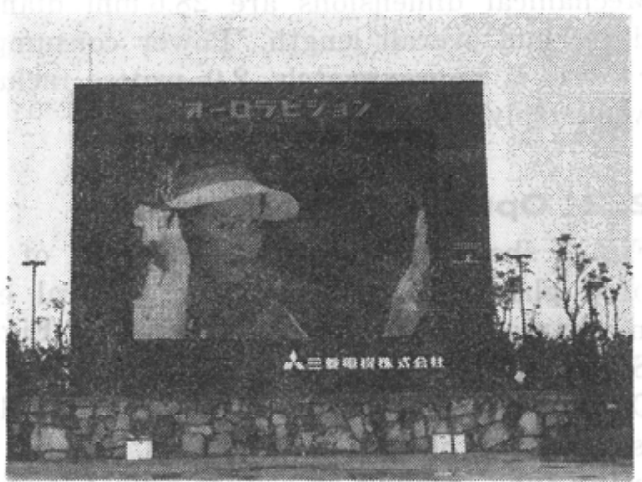

Fig. 7 Giant Display System Installed at Portopia' '81, Kobe, Japan.

ample, race-tracks, theme parks, convention centers, advertising towers, amusement applications, etc.

\section{References}

(1) K. Awazu and H. Kobayashi: Conf. Illum. Eng. Inst. Tokyo, No. 21 (1981)

(2) K. Kurahashi and H. Kobayashi et al: SID International Symposium, April, 1981.

(3) Y. Shimizu and H. Kobayashi et al: IEEE Chicago Spring Conference on Consumer Electronics, 1981.

Receivec 5 Sept. 1981; Revision Received 5 June. 1981 